Cahiers

d'ethnomusicologie

\section{Cahiers d'ethnomusicologie}

Anciennement Cahiers de musiques traditionnelles

$10 \mid 1997$

Rythmes

\title{
Kazakhstan. Musique d'Almatï
}

AIMP XLVI, 1996

\section{Pribislav Pitoëff}

\section{(2) OpenEdition}

Journals

Édition électronique

URL : http://journals.openedition.org/ethnomusicologie/938

ISSN : 2235-7688

Éditeur

ADEM - Ateliers d'ethnomusicologie

\section{Édition imprimée}

Date de publication : 1 décembre 1997

Pagination : $347-348$

ISBN : 2-8257-0579-9

ISSN : 1662-372X

Référence électronique

Pribislav Pitoëff, «Kazakhstan. Musique d'Almatï », Cahiers d'ethnomusicologie [En ligne], 10 | 1997, mis en ligne le 06 janvier 2012, consulté le 21 avril 2019. URL : http://journals.openedition.org/ ethnomusicologie/938

Ce document a été généré automatiquement le 21 avril 2019

Tous droits réservés 


\title{
Kazakhstan. Musique d'Almati
}

\author{
AIMP XLVI, 1996
}

Pribislav Pitoëff

\section{RÉFÉRENCE}

Kazakhstan. Musique d'Almati.Enregistrements (1994) de Wolf Dietrich, notice de Baldïrgan Bayaqadamova, Wolf Dietrich et Mark Kirchner. 1 CD AIMP XLVI, VDE-Gallo 910, 1996.

1 La discographie existante sur les musiques du Kazakhstan étant bien mince (nous y reviendrons plus bas), nous avons accueilli ce disque avec une oreille gourmande. Les enregistrements ont été réalisés auprès de treize artistes qui proviennent de différentes régions du pays, mais qui sont tous enseignants ou étudiants avancés du Conservatoire d'Almatï (ex Alma-Ata). Comme le précise la notice, il s'agit donc d'interprétations qui, tout en puisant leurs sources sur le terrain, ne représentent pas exactement la musique dans sa pratique traditionnelle.

2 A coté de la musique populaire d'amateurs, Il existe au Kazakhstan, comme dans tous les pays d'Asie centrale (pour ne parler que de cette région), une tradition ancienne de musiciens et chanteurs professionnels. Les créations de ces auteurs-compositeurs ont été transmises de façon orale jusqu'à nos jours. Ainsi sur ce disque, plus de la moitié des airs sont attribués à des compositeurs identifiés - lesquels ont tous vécu au siècle passé, fautil préciser.

Différents genres et formes de la musique kazakhe sont présentés ici. Le zhir est un poème narratif à caractère épique, dont un extrait figurte en plage 1.

Dans les pièces complètes, alternent des récitatifs en prose, des chants versifiés et des interludes instrumentaux. Le tolgaw est un genre didactique dans lequel le poète expose sa conception du monde; on regrette que la notice ne précise pas si les deux exemples donnés (plages 2 et 8 ) sont des compositions de l'interprète, et que les textes ne soient pas donnés plus en longueur. Le terme (plages 9,10 et 11) désigne tout à la fois une forme poétique construite sur des vers de sept syllabes et un style récitatif. Le än se distingue 
par son organisation strophique (plages 12,13); il appartient, semble-t-il, à la musique populaire. Le zhoqtaw est un chant funéraire qui appartient au répertoire populaire; toutefois la version présentée (plage 20) ici est instrumentale; elle a été composée pour le luth par un poète ancien (1854-1921) à la mort de sa fille.

Dans le répertoire instrumental de la musique kazakhe, les küy tiennent une place importante. Joués au luth dombra ou à la vièle, mais aussi parfois à la flûte de berger (indication signalée pour la plage 4), ce sont de véritables compositions exigeant une grande virtuosité. Ils sont créés par des musiciens professionnels et les plus anciens remontent au XVIII ${ }^{\mathrm{e}}$ siècle. Les küy sont le plus souvent des airs de musique dite «à programme »: ils relatent ou décrivent un épisode historique (plage 3), une histoire de vie (plage 17) ou un événement (plage 4, 5, 7), une légende (plage 19), des personnages ou des animaux (l'oie sauvage plage 6, le cygne plage 16) ou la nature (plage 21).

6 Les Kazakhs possèdent peu d'instruments de musique. Le dombra est un luth à long manche muni de frettes, tendu le plus souvent de deux cordes en boyau accordées à la quarte (ou parfois à la quinte) et jouées simultanément. C'est l'instrument emblématique de la musique kazakhe, pratiqué par les musiciens amateurs et professionnels. Il figure en solo ou accompagnant un chant sur seize des vingt et une plages du disque. Des luths de facture proche, mais dont les techniques de jeu et les styles diffèrent largement, se rencontrent dans tout le monde musical turc.

7 La vièle qilqobïz (ou qobüz, souvent écrit kobuz ou kobiz) à deux cordes en crin de cheval est munie d'un manche sans frette; la caisse a la particularité de n'être couverte d'une peau que sur sa moitié inférieure (plages 1, 4, 7, 16 et 19). On trouve des vièles de ce type chez les Kirghizes (où elle est appelée kiak), chez les Karakalpaks et chez les Ouzbeks d'Ouzbékistan et d'Afghanistan.

A coté de ces deux instruments, existent une flûte à embouchure terminale zibzïgï (ou sibizgi) et une guimbarde (shan kobiz) qui ne figurent pas sur ce disque.

A notre connaissance, la discographie est très limitée. Deux $C D$, que nous n'avons pas eus en main, sont publiés par World Music Library : Kazakhstan. Music of Kazakhstan (WML CD 5166) et Kazakhstan. Dombra Music of Kazakhstan (WML CD 5199). Quant au disque Estonie, Lettonie, Kazhakstan (Le Chant du monde, LDX 174923), quatrième CD de l'anthologie Voyage en URSS: Anthologie de la musique instrumentale et vocale des peuples d'URSS (qui est une reprise de l'édition en 33 tours), il s'agit d'une publication sommairement documentée et dont on peut mettre en doute la rigueur ethnographique du collectage.

Par ailleurs, une bonne présentation de la musique du Kazakhstan se trouve dans l'ouvrage de Viktor M. Beliaev : Central Asian Music, dans l'édition annotée, et traduite en anglais de Mark Slobin, publié par Wesleyan University Press (Middletown, 1975).

Wolf Dietrich apporte donc avec ce disque une contribution importante à la connaissance de la musique kazakhe. Souhaitons que ce spécialiste des musiques grecque et turque nous livre d'autres publications sur les différentes pratiques musicales de ce pays. 